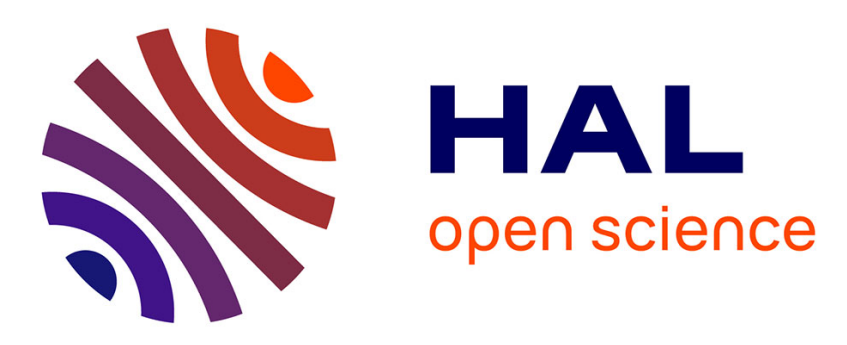

\title{
Bayesian updating of a cracking model for reinforced concrete structures subjected to static and cyclic loadings
}

Henriette Marlaine Imounga, Emilio Bastidas-Arteaga, Rostand Moutou Pitti, Ekomy Ango

\section{To cite this version:}

Henriette Marlaine Imounga, Emilio Bastidas-Arteaga, Rostand Moutou Pitti, Ekomy Ango. Bayesian updating of a cracking model for reinforced concrete structures subjected to static and cyclic loadings. Fracture, Fatigue, Failure and Damage Evolution, 3, 2021, Fracture, Fatigue, Failure and Damage Evolution, Conference Proceedings of the Society for Experimental Mechanics Series. hal-03042597

\section{HAL Id: hal-03042597 \\ https://hal.science/hal-03042597}

Submitted on 24 Dec 2020

HAL is a multi-disciplinary open access archive for the deposit and dissemination of scientific research documents, whether they are published or not. The documents may come from teaching and research institutions in France or abroad, or from public or private research centers.
L'archive ouverte pluridisciplinaire HAL, est destinée au dépôt et à la diffusion de documents scientifiques de niveau recherche, publiés ou non, émanant des établissements d'enseignement et de recherche français ou étrangers, des laboratoires publics ou privés. 


\title{
Bayesian updating of a cracking model for reinforced concrete structures subjected to static and cyclic loadings
}

\author{
Imounga H.M. ${ }^{1,2}$, Bastidas-Arteaga ${ }^{2}$ E., Moutou Pitti R. ${ }^{3,4}$, Ekomy Ango S. ${ }^{4}$ \\ ${ }^{1}$ Université des Sciences et Technique de Masuku, EPM, BP 941, Franceville, Gabon \\ ${ }^{2}$ UBL, Université de Nantes, GeM, BP 92208, 44000 Nantes, France \\ ${ }^{3}$ Université de Clermont Auvergne, CNRS, SIGMA Clermont, Institut Pascal, BP 10448, \\ F-63000 Clermont-Ferrand, France \\ ${ }^{4}$ IRT, CENAREST, Libreville, Gabon
}

\begin{abstract}
Several reinforced concrete structures fail by fatigue loads. The effects of this type of loading are complex. Many mechanical models based on the damage theory could be used to represent the behavior of reinforced concrete under cyclic loading. Their use requires, among others, knowledge of the material characteristic parameters and its related uncertainties that could be determined from experimental tests. However the models are time-consuming and the experimental data scarce. In this paper we propose a Bayesian network based methodology to propagate uncertainties in the damage theory model. The proposed methodology is useful to identify the uncertainties of the damage model used when some parameters are measured. The methodology is illustrated with a reinforced concrete beam subjected to cyclic loading. The results obtained were compared with those of the experimental tests to validate the proposed methodology. The good agreement indicates that our approach is capable of propagating uncertainties and integrating data from experimental tests. The proposed approach could be also used to identify the uncertainties of the model used by introducing experimental measurements.
\end{abstract}

Keywords: Cracking, cyclic loading, Bayesian network, reinforced concrete, damage theory

\section{INTRODUCTION}

During their operation, reinforced concrete structures are subjected to stresses of several types responsible for their rapid deterioration. To reproduce or predict the degradation processes of these structures, numerical models validated by experimental tests have been developed for many authors. In the case of fatigue loads, several models based on the damage theory are useful to describe the mechanical behavior of concrete after each loading cycle (loading-unloading) [1]-[3]. The purpose of these models is to assess the effects of micro-cracking in concrete, using a bounded variable (scalar or tensor) called the damage variable. For the models of damage, the behavior law relating stress to deformation is written as follows:

$$
\boldsymbol{\sigma}=(\mathbf{I}-\mathbf{D}) \mathbf{C}: \boldsymbol{\varepsilon}
$$

where $\sigma$ is the stress tensor, $\varepsilon$ the strain tensor, I the unity tensor, $\mathrm{C}$ is the tensor of elastic behavior and $\mathrm{D}$ is the tensor of damage. These models take into account intrinsic parameters of the material such as the elastic modulus, the stresses of tension/compression or even the parameters of hardening; which are determined from experimental tests. These tests may contain uncertainties related to the implementation of the tests, the variability of the material properties, the errors in the measurements and the used calculation methods. In this context, the main objectives of this work is to propose a methodology based on Bayesian networks that could be useful to propagate uncertainties in the damage model and that could be updated with some measurements. The first part of this work describes the constitutive equations of the used damage model (Section 2). The numerical implementation and the description of the proposed Bayesian network based methodology are detailed in Section 3. Finally, the results are presented and discussed in Section 4. 


\section{CONSTITUTIVE EQUATIONS OF THE DAMAGE MODEL}

The model used is an isotropic damage model developed by Richard et al. [3], and implemented in Castem codes. In this model, the damage variable representing the degradation of the elasticity modulus, due to micro-cracking, is a scalar which varies between 0 for healthy concrete and 1 for cracked concrete. The constitutive equations are formulated in the framework of the thermodynamics of irreversible processes and the model accounts for residual deformations, hysteretic behaviors and unilateral effects (opening - closing of the crack) of concrete [3]. The different state laws based on the inequality of Clausius - Duhem - Trusdell [4] are summarized by the following equations:

$$
\left\{\begin{array}{c}
\boldsymbol{\sigma}=\mathrm{E}\left((1-\mathrm{D})<\varepsilon_{x}>_{+}+<\varepsilon_{x}>_{-}\right)+2(1-D) \mu \boldsymbol{\varepsilon}+2 D \mu\left(\boldsymbol{\varepsilon}-\boldsymbol{\varepsilon}^{\boldsymbol{\pi}}\right) \\
\boldsymbol{\sigma}^{\boldsymbol{\pi}}=2 D \mu\left(\boldsymbol{\varepsilon}-\boldsymbol{\varepsilon}^{\boldsymbol{\pi}}\right) \\
\boldsymbol{Y}=\frac{E}{2}<\varepsilon_{x}>_{+}^{2}+\mu \boldsymbol{\varepsilon} . \boldsymbol{\varepsilon}-\mu\left(\boldsymbol{\varepsilon}-\boldsymbol{\varepsilon}^{\boldsymbol{\pi}}\right) .\left(\boldsymbol{\varepsilon}-\boldsymbol{\varepsilon}^{\boldsymbol{\pi}}\right)
\end{array}\right.
$$

where $\mu$ is a shear coefficient, $\boldsymbol{\sigma}^{\boldsymbol{\pi}}$ is the frictional tensor, $\boldsymbol{\varepsilon}^{\boldsymbol{\pi}}$ is the sliding tensor and $\boldsymbol{Y}$ is The damage energy released rate. Equation (3) gives the expression of the scalar damage variable.

$$
\mathrm{D}=1-\frac{1}{1+\left(A_{\text {Dir }} H\left(<\varepsilon_{i j}>_{+}<\sigma_{i j}>_{+}\right)+A_{\text {Ind }}\left(1-H\left(<\varepsilon_{i j}>_{+}<\sigma_{i j}>_{+}\right)\right)\right)\left(Y-Y_{0}\right)}
$$

where $A_{\text {Dir }}$ represent the brittleness in tension, $A_{\text {Ind }}$ the brittleness in compression, $Y_{0}$ the damage initial threshold and $\mathrm{H}$ is Heaviside.

\section{NUMERICAL IMPLEMENTATION AND PARAMETERS UPDATING}

\section{Problem description}

The approach will be illustrated based on the configuration of a test conducted by Wang et al. [5] is presented. The specimens are reinforced concrete beams of dimension $300 \mathrm{~mm} \times 120 \mathrm{~mm} \times 1500 \mathrm{~mm}$, subjected to a cyclic bending at three points $(10,000$ cycles) with an alternating point load varying between $5.4 \mathrm{kN}$ and $18 \mathrm{kN}$. The geometry of the beam as well as the configuration of the loading is presented in Figure 1.

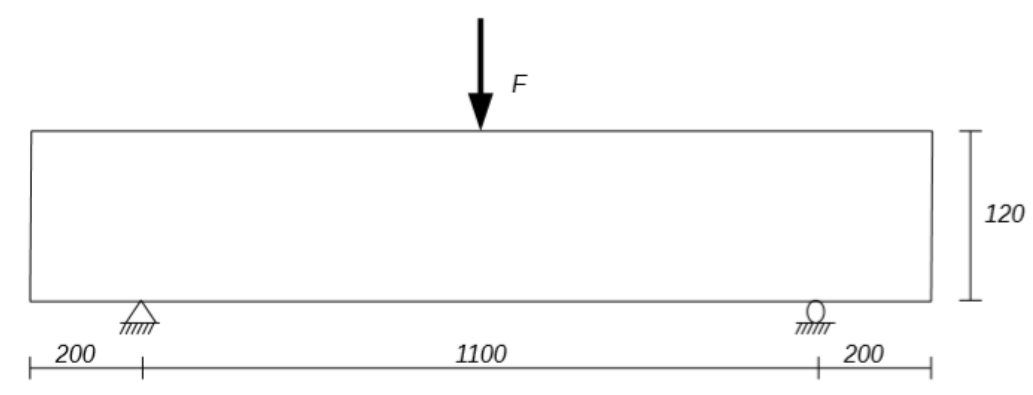

Figure 1 - Beam geometry configuration

\section{Mechanical model}

The beam was modeled in Castem finite element software in 2D case with the assumption of plane stresses. The input parameters of the model are presented in Table 1. The Young's modulus, the tensile strength and the applied load are modeled as random variables whose laws and their parameters are also defined in Table 1. The other parameters (Brittleness in tension and in compression, kinematics and nonlinear hardening) of the model are taken from [1], [3], and [6] for ordinary concretes because we don't have information on this. These parameters are not easy to measure during experimental tests unlike others such as the deflection whose observations will be used as described in the following sections. 1000 Monte Carlo simulations 
were performed for each random variable. The outputs of the finite element code are the values of the mid-span deflection $(\mathrm{w})$ and the stress of Von Mises $\left(\sigma_{\mathrm{VM}}\right)$ in the direction of loading.

In order to integrate the test data into the Bayesian network (Section 0), the properties (material characteristic, geometry, loading, etc.) of the numerical model are the same as those of the real beam.

Table 1 - Input parameters of mechanical model

\begin{tabular}{llll}
\hline Parameters & & Notation & Value \\
\hline Elasticity modulus & $(\mathrm{MPa})$ & $E$ & Lognormal $(\mu=35000 ; \mathrm{COV}=0.12)$ \\
Tensile strength & $(\mathrm{MPa})$ & $f_{t}$ & Lognormal $(\mu=3.5 ; \mathrm{COV}=0.13)$ \\
Concentrate load & $(\mathrm{N})$ & $F$ & Uniform on the interval $[5.4 ; 18] \times 10^{3}$ \\
Damage initial threshold $\left(\mathrm{Jm}^{-3}\right)$ & $Y_{0}$ & 1000 \\
Poisson ratio & & $v$ & 0.2 \\
Brittleness in tension & & $A_{\text {Dir }}$ & $1 \times 10^{-2}$ \\
Brittleness in compression & $A_{\text {Ind }}$ & $5 \times 10^{-4}$ \\
Kinematics hardening & $(\mathrm{Pa})$ & $\gamma_{0}$ & $7 \times 10^{9}$ \\
Nonlinear hardening & $(\mathrm{Pa})$ & $a_{0}$ & $7 \times 10^{-7}$ \\
\hline
\end{tabular}

\section{BAYESIAN CONFIGURATION AND UPDATING}

The configuration of the Bayesian network is presented in Figure 2. It is constructed from the input random variables and output data estimated from the finite element code. The input random variables $\left(\mathrm{E}, \mathrm{F}\right.$ and $\mathrm{f}_{\mathrm{t}}$ ) are modeled as parent nodes, and the output parameters $\left(\mathrm{w}, \sigma_{\mathrm{VM}}\right)$ as child nodes. All nodes are considered discrete and divided into a number of states within predefined bounds. The details of the discretization and the a priori information of the different nodes are summarized in

Table 2.

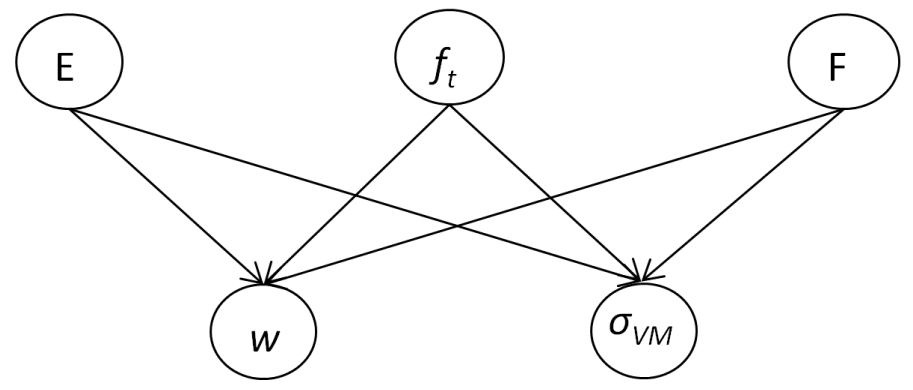

Figure 2 - Bayesian network setup

Table 2 - Discretization of nodes and a priori information for the Bayesian network

\begin{tabular}{llll}
\hline Nodes & Number of states & Prior distribution & Boundaries \\
\hline$E(\mathrm{MPa})$ & 20 & $\mathrm{LN}(\mu=35000 ; \mathrm{COV}=0.12)$ & {$[20 ; 50] \times 10^{3}$} \\
$f_{t}(\mathrm{MPa})$ & 20 & $\mathrm{LN}(\mu=3.5 ; \mathrm{COV}=0.13)$ & {$[1 ; 5]$} \\
$F(\mathrm{~N})$ & 20 & Uniform & {$[5.4 ; 18] \times 10^{3}$} \\
$w(\mathrm{~mm})$ & 40 & - & {$[3 ; 0]$} \\
$\sigma_{V M}(\mathrm{MPa})$ & 20 & - & {$[10 ; 80] \times 10^{3}$} \\
\hline
\end{tabular}


The methodology used to update the deflection and the Von Mises stress requires an iteration of mechanical (finite element code) and probabilistic analyses (Monte Carlo simulation, Bayesian network) see Figure 3. Monte Carlo simulations of the input random variables of the mechanical model $\left(\mathrm{E}_{\mathrm{and}} \mathrm{f}_{\mathrm{t}}\right)$ and of the load $(\mathrm{F})$, carried out in the Matlab software, are introduced into the Castem code to calculate 1000 values of the output parameters of the model $\left(\mathrm{w}, \sigma_{\mathrm{VM}}\right)$. These values allow building the conditional probability tables of the nodes of the Bayesian network. This step allows propagating the uncertainties of the input parameters to the outputs. The data from the experimental tests observed on the mid-span deflection are then introduced into the Bayesian network as evidence in order to update the probabilities of all the nodes. The deflection measurements can also be used to indirectly identify the mean values, standard deviation and type of distribution of other mechanical parameters. The Bayesian network outputs are the posteriori probabilities of each of the nodes, from which the laws of the nodes and their parameters (mean, standard deviation) could be determined after updating.

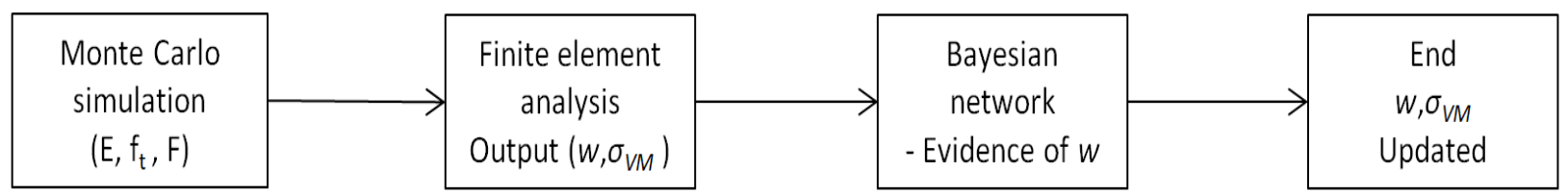

Figure 3 - Flowchart of the proposed methodology

\section{RESULTS AND DISCUSSIONS}

The values of the maximum mid-pan deflection before and after the update with the Bayesian network are presented in Table 3. The mean deflection value for 10,000 cycles to the unload is also presented in Table 3 [5]. We can note that the mean values of w obtained from the Bayesian network are higher than the experimental value; and that obtained without the addition of evidence is closer to experimental value. In addition, the value of the maximum tension stress increases with the introduction of the evidence of the deflection. This difference shows on the one hand that the uncertainties linked to the parameters of the concrete propagate in the mechanical model before the update, and on the other hand that are linked to the experimental evidence propagated through the Bayesian network. Uncertainties on experimental measurements are more important than the uncertainties linked to the parameters.

Table 3 - Deflection and tensile stress means

\begin{tabular}{|l|l|l|l|}
\hline Parameters & No evidence & With evidence & Experimental data \\
\hline$w(\mathrm{~mm})$ & 0.53 & 0.82 & 0.6 \\
\hline$\sigma_{V M}(\mathrm{MPa})$ & 51.12 & 61.62 & - \\
\hline
\end{tabular}

These preliminary results can be improved by adjusting the limit values, the number of states or even the number of Monte Carlo's simulations that were fixed at 1000 simulations because of the computation time.

Figure 4 shows the deflection histograms with and without evidence. We can see that the a posteriori histogram of w adjusts with the introduction of evidence from the trials. This adjustment is due to the fact to had integrated additional information on the deflection. The proposed methodology therefore makes it possible to update the output parameters of the mechanical model by integrating experimental measurements. 


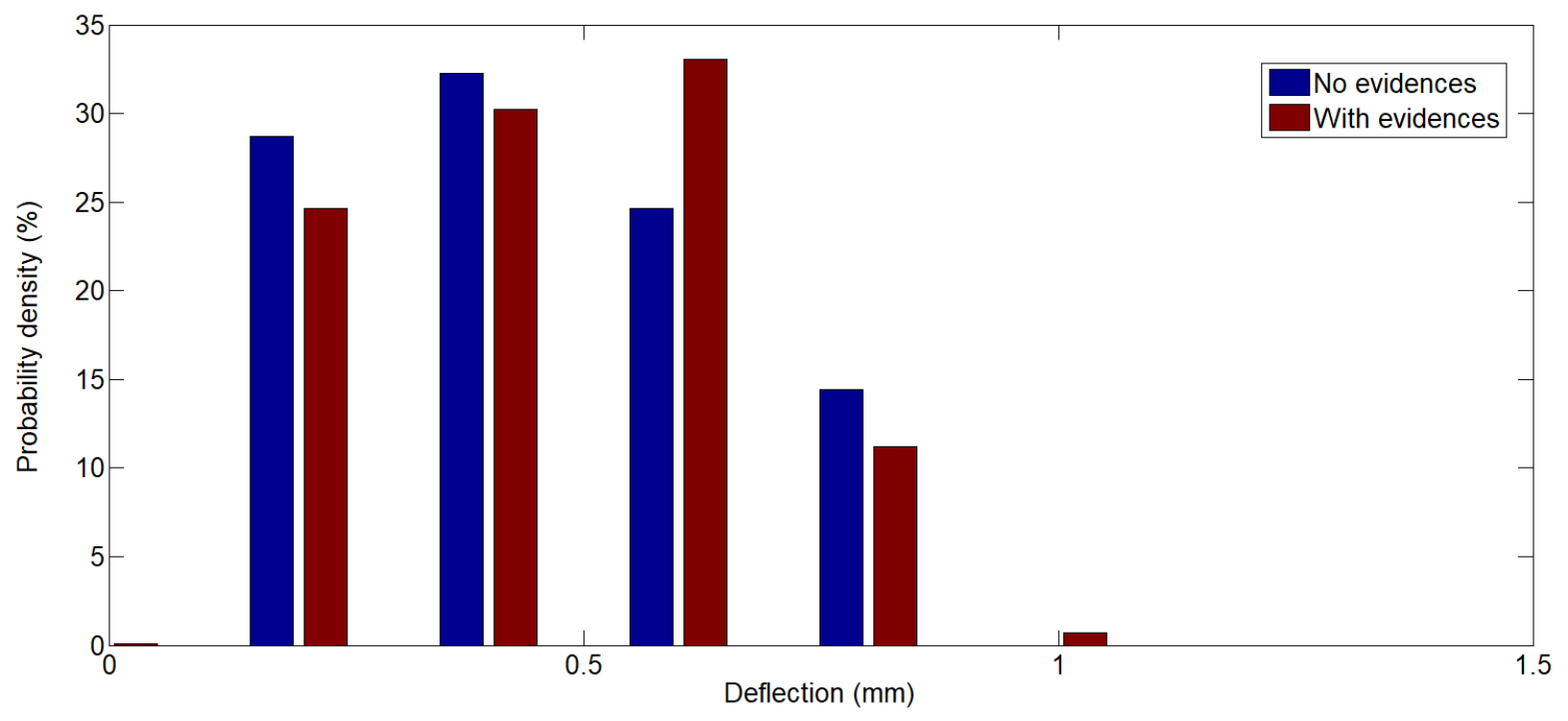

Figure 4 - Comparison of a posteriori histograms of $w$

\section{CONCLUSION}

This paper proposes a methodology which combines a mechanical model and probabilistic approaches. The methodology makes it possible to account for the uncertainties linked to the material, loading, and experimental measurements. It is also useful to integrate the observations of the tests and to update the other parent nodes by using Bayesian networks. The results show that the uncertainties related to the experimental measurements are greater than those linked to the characteristics of the material in view of the difference between the numerical values of the deflection before and after the introduction of the evidence. Although the number of simulations is small, the numerical values of the deflection are not very far from those of the experimental test. Future work will focus on the analysis of cracking under cyclic load, taking into account the phenomena of opening and closing of the crack. Another aspect of the improvement of the methodology will be the consideration of the geometry of the crack, the space between the cracks and the propagation of the fatigue cracks. Finally, the parameters of the damage model whose values are taken from the literature will be modeled as random variables in order to evaluate the effects of their uncertainties on the output parameters of the mechanical model.

\section{ACKNOWLEDGMENTS}

The financial support of the Regional Council of 'Pays de la Loire' within the framework of the BUENO 2018-2021 research program (Durable Concrete for Offshore Wind Turbines) is gratefully acknowledged.

\section{REFERENCES}

[1] La Borderie C., "Unilateral effects for damage-like materials: modelling and application to concrete structures," PhD thesis, University Paris VI, Paris, 1991.

[2] M. Matallah and C. La Borderie, "Inelasticity-damage-based model for numerical modeling of concrete cracking,” Engineering Fracture Mechanics, vol. 76, no. 8, pp. 1087-1108, May 2009.

[3] B. Richard, F. Ragueneau, C. Cremona, and L. Adelaide, "Isotropic continuum damage mechanics for concrete under cyclic loading: Stiffness recovery, inelastic strains and frictional sliding," Engineering Fracture Mechanics, vol. 77, no. 8, pp. 1203-1223, May 2010.

[4] Lemaître J., Chaboche JL., Solid material mechanics. Dunod, 2004.

[5] X.-H. Wang, E. Bastidas-Arteaga, and Y. Gao, "Probabilistic analysis of chloride penetration in reinforced concrete subjected to pre-exposure static and fatigue loading and wetting-drying cycles," Engineering Failure Analysis, vol. 84, pp. 205-219, Feb. 2018. 
[6] Ragueneau F., Mazars J., La Borderie C., "Damage model for concrete including residual hysteretic loops: application to seismic and dynamic loading," In: Framcos 3 - 3rd conference on fracture mechanics of concrete structures, vol. 1, no. 1, pp. 685-96, 1998. 